\title{
Impact of Early Loss of Lower First Permanent Molars on Third Molar Development and Position
}

\author{
Amanda Silva de Sousa ${ }^{1}$, Fabrizza Roberta Lemos Araújo ${ }^{1}$, Giulliana Simões Castro Villela ${ }^{1}$, David \\ Normando 1 (1)
}

${ }^{1}$ Department of Orthodontics, School of Dentistry, Federal University of Pará, Belém, PA, Brazil.

Correspondence: David Normando, School of Dentistry, Federal University of Pará, Avenida Pedro Àlvares Cabral, 880, Apto 2500, Bairro Umarizal, Belém, Pará, Brazil.66050400.E-mail: davidnormando@hotmail.com

Academic Editor: Catarina Ribeiro Barros de Alencar

Received: 14 April 2020 / Review: 29 August 2020 / Accepted: 09 October 2020

How to cite: Sousa AS, Araújo FRL, Villela GSC, Normando D. Impact of early loss of lower first permanent molars on third molar development and position. Pesqui Bras Odontopediatria Clín Integr. 2021; $21:$ e0072. https://doi.org/10.1590/pboci.2021.050

\begin{abstract}
Objective: To evaluate the effects of unilateral loss of the lower first permanent molar (L6) on the position and development of the lower third molar (L8). Material and Methods: Fifty-four panoramic radiographs of subjects with unilateral loss of L6 were examined. The L8 on the side of the L6 loss was compared with the L8 in the hemiarch without L6 loss (contralateral). The effect of L6 loss on the positioning of L8 was examined in all the samples $(n=54)$, whereas the effect on the development of the third molar was examined in 38 patients with L8 with incomplete root formation. The Signs statistical test was used to evaluate the comparison between loss and contralateral hemiarches. Results: In 20 (37\%) of 54 subjects, the L8 was better positioned in the hemiarch with loss of the lower first molar $(\mathrm{p}<0.001)$ compared with the control side. In the remaining 34 subjects, no difference was found. When only the L8 considered as impacted on the control side was examined $(\mathrm{n}=30)$, the cases with better positioning on the side with L6 loss increased to $66.6 \%(\mathrm{p}<0.001)$. Conclusion: The loss of lower first molars improves the position of the lower third molar during its active eruption, mainly when the lower third molar is impacted. However, L6 loss does not affect the root development of lower third molars.
\end{abstract}

Keywords: Orthodontics; Tooth Loss; Third Molar; Radiography, Panoramic. 


\section{Introduction}

The loss of lower first permanent molars is regarded as the most prevalent tooth loss because these are the permanent teeth most likely to decay and to have developmental defects [1]. Such tooth loss can lead to remarkable clinical alterations in the positioning of the neighboring and antagonist teeth [2,3] and even in the facial profile [4]. Studies have reported that the extraction of first molars causes a lingual inclination of the lower incisors [4-9], enabling the migration of the adjacent teeth into the extraction side2,5 and increasing the eruption space of third molars $[2,10,11]$. All these can justify the need for orthodontic treatment and rehabilitation due to the occlusal changes' complexity [3].

As the potential of orthodontic treatments such as slow maxillary expansion is nowadays clear, knowing the effects of infraocclusion on mandibular growth could have a significant impact on treatment planning [12].

Recent studies have shown that before the age of 12 years, the loss of permanent first molars might have an accelerating effect on the development of the third molars on the extraction side compared with the contralateral teeth [5]. Because these are the last teeth to complete their development and eruption process $[8,9]$, there is sometimes not enough space for a normal eruption, leading to a total or partial impaction. Therefore, a major issue in clinical practice is the diagnosis of the need for either preservation or surgical removal of third molars [6], which are the teeth most likely to remain retained [7,8], especially in the lower dental arch [9].

The eruption of permanent molars can be disturbed either by primary retention, which represents an arrest in the eruption process before the molar has penetrated the oral mucosa or by secondary retention, which represents an arrest in the eruption process after the molar has penetrated the oral mucosa. The etiology of failure of eruption is related to some disturbance of physiological growth and tooth development [13].

Local morphologic and dental factors can affect the development stage of a dental element6, which can be accelerated or delayed in the presence of anatomic differences between individuals [14]. Failure of eruption of permanent molars is an anomalous condition whose prevalence in a normal population is about $0,06 \%$ [13]. Thus, when the first permanent molars are lost, a mesial inclination of the remaining posterior teeth may occur, which can promote the normal eruption of the third molars [1]. However, the effect on the eruption pattern of the lower third molars is still under debate because the impaction prediction has not been scientifically proven [15,16]. Furthermore, this issue has been evaluated by X-ray measurements instead of the routine clinical approach of a direct visual examination of images.

The aim of this study was to evaluate whether unilateral loss of a permanent first molar has an effect on the position and development of the lower third molars in the same hemiarch.

\section{Material and Methods}

This study was approved by the Ethics Committee on Human Research of the Institute of Health Sciences of the Federal University of Pará (Protocol No. 498024).

The research was carried out through a retrospective analysis of panoramic radiographs that were part of the routine records of 54 patients in 10 private orthodontics offices. The patients should have all permanent teeth, including the third molars, except for unilateral loss of the lower first molar. Patients with previous orthodontic treatment were not included. Fourteen males and 40 females were selected, with a median age of 31 (range, 14 to 48.1 ) years. 
Although recovery was done to determine when the loss of the lower first permanent molar occurred, it was not possible to precisely determine such time because $95 \%$ of the patients could not tell exactly when they lost their first tooth; they confirmed, however, that the loss happened at least 5 years ago.

The radiographs were scanned and uploaded on Microsoft PowerPoint (Redmond, WA, USA). A blackboard was added for each radiograph image, with extension of the mesial face of the lower $2^{\circ}$ permanent molar on the right side to the mesial face of the $2^{\circ}$ permanent molar on the left side (Figure 1 ), to avoid identification of which side the loss of the lower first permanent molar occurred on. Through visual inspection of the radiographs, the tooth development and position of the lower third molar on the side with loss were directly compared with those of the contralateral tooth in the hemiarch without loss (control side).

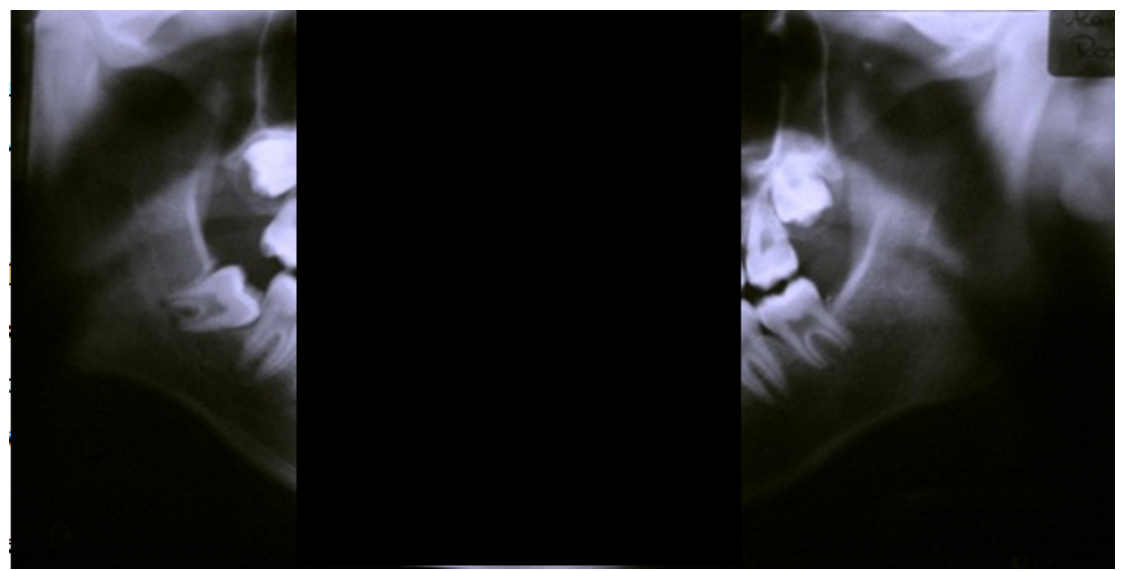

Figure 1. Panoramic radiography examined with a blackboard to avoid identification of which side the loss of first molar occurred on.

Four senior examiners, two radiologists and two orthodontists, who had at least 10 years of professional experience, classified the lower third molars on both sides according to the tooth positioning level, as either impacted or normal, and the tooth development [17]. They compared the third molars on the loss side with the control hemiarch, evaluating the vertical and sagittal positions; the examiners were blinded to the control and loss sides. A positive sign (+) indicated the better positioned tooth, and a negative sign (-) denoted the worst positioned one; null (o) indicated that it was not possible to distinguish either. The development of each tooth was appraised by studying the radiographs, which were graded on a scale from 0 to 10 according to the Nolla stages of development of mandibular and maxillary teeth [17]. The same methodology was used to compare the tooth development. The majority of the evaluations (4xO or $3 \mathrm{x} 1)$ were taken as the final diagnosis. In case of a tie among the examiners (2x2), an orthodontist was invited as a fifth examiner to establish the final diagnosis. The sample was subdivided according to the presence or absence of the third molar's impaction on the control side.

The influence of lower first molar loss on the degree of tooth development of the molar was examined in 38 patients, which consisted of 10 males and 28 females, with a mean age of 21.8 years, whose third molars presented incomplete root formation.

In the statistical analysis, direct comparison of the third molar position and tooth development between the control and loss sides were done by applying the Signs test at $\mathrm{p}<0.0$, which is a nonparametric test for matched or paired data. The approach was to analyze only the signs of the difference scores. Specifically, we determined a critical value such that if the smaller of the number of positive or negative signs is less than or equal to that critical value, then we reject the null hypothesis in favor of the research hypothesis and if the 
smaller of the number of positive or negative signs is greater than the critical value, then we do not reject the null hypothesis. The same level of statistical significance was used for all comparisons.

\section{Results}

The comparison of the positioning of the third lower molar between the side with and the side without loss of the adjacent first molars showed that in $20(37.03 \%)$ cases, the third lower molar on the loss side was better positioned than that on the control side. In the remaining 34 cases $(62.97 \%)$, the examiners found no difference (Figure 2). No lower third molar on the side without loss was considered as better positioned.

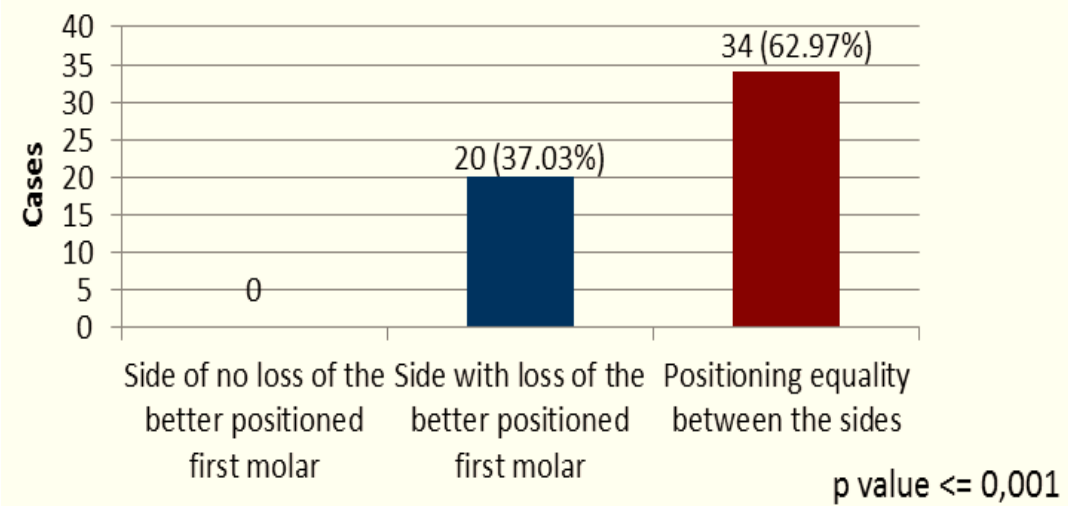

Figure 2. Comparative analysis of the positioning of the third lower molar between the side with and without loss of the adjacent first molars $(n=54)$.

After the analysis of the third molars on the control side, 30 lower third molars were considered as impacted by the evaluators. The analysis of this group of patients showed that in 20 cases (66.6\%), the third molar on the loss side was better positioned, whereas in the other 10 cases (33.4\%), the third molar was considered to have the same positioning (Figure 3).

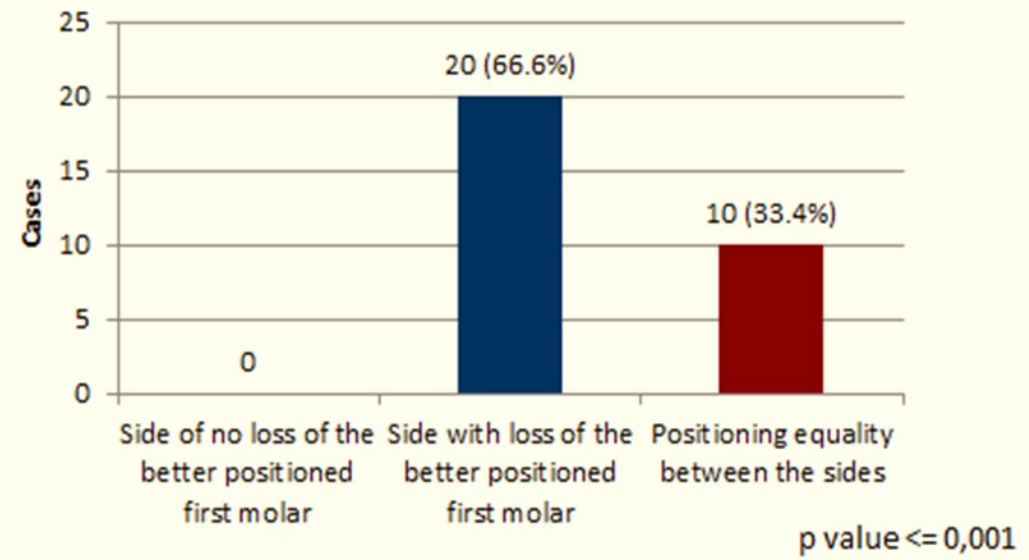

Figure 3. Comparative analysis in patients where the positioning of lower third molars in the control side were considered impacted by the evaluators $(n=30)$.

The comparison of the degree of root development of the third molars in the 38 cases that presented third molar development indicated that in 33 (86.9\%) cases, the third molars on both sides were considered to be at the same stage of root development; only in $5(13.1 \%)$ cases were the third molars on the loss side 
considered to be in a more advanced stage (Figure 4). The statistical analysis showed no difference in the degree of dental development of the lower third molars between the side with lower first molar loss and the control side $(\mathrm{p}=0.07)$.

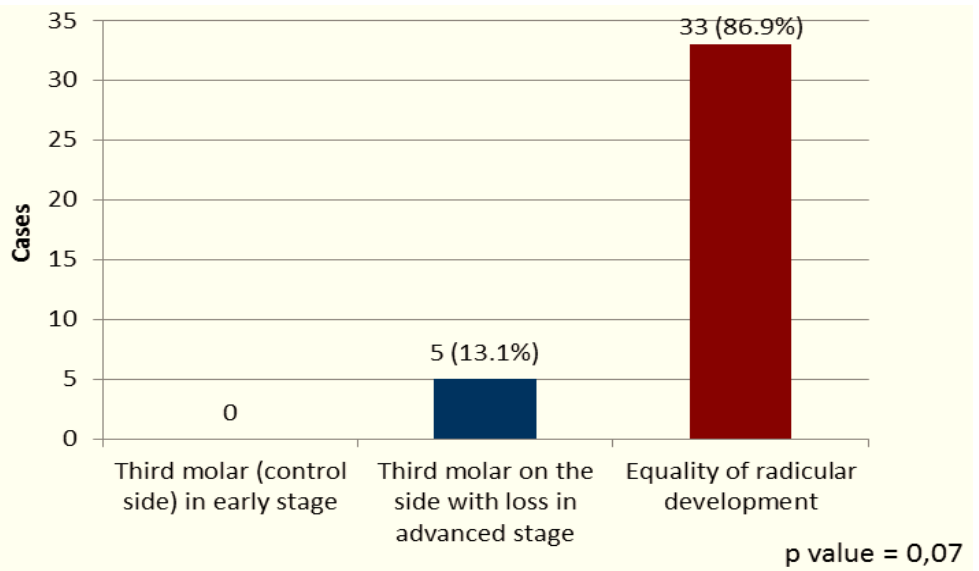

Figure 4. Comparative analysis of the degree of root development of the lower third molars adjacent to hemi-arches with loss of the lower first permanent molars and control side $(n=38)$.

\section{Discussion}

Spontaneous changes resulting from mandibular first molar loss are important for either orthodontic or prosthodontic treatment planning. This study tried to determine whether the spontaneous changes in the position of lower third molars were associated with the extraction of the lower first permanent molar.

The findings showed that in about one third $(\mathrm{n}=20)$ of the total sample $(\mathrm{n}=54)$, the lower third molar was better positioned in the hemi-arch adjacent to the loss of the lower first molar $(\mathrm{p}<0.001)$. However, when only the third molars considered as impacted on the control side were examined, the better positioning of the third molar on the side of the first molar loss increased to $2 / 3$. These results provide evidence that the presence of impaction is an imperative condition for improving the eruptive pattern of the adjacent third molar as a consequence of first molar loss.

A previous study that investigated the effects of orthodontic treatment with four first molar extractions on the third molars has suggested that orthodontic treatment involving extractions of the permanent first molars increases the eruption spaces of third molars and decreases their impaction [18]. In the present work, only subjects who underwent unilateral extractions because of caries and not for orthodontic purposes were included. The findings confirm that the better positioning of the third molar improves even when patients are not submitted to orthodontic treatment [19]. However, since spontaneous space closure after 3rd molar loss is a mix of 2 nd and 3rd mesial movement and premolars distal inclination [2,3] that are unpredictable [2,19], it is likely that the improvement in third molars position is associated with the amount of mesial movement of the second molar, something that can only be controlled by orthodontic treatment.

Surgical uncovering is indicated if the tooth has an adequate position and angulations and presents an incomplete root and a growth potential, which can facilitate tooth eruption. The majority of impacted teeth erupt if hard- or soft-tissue obstructions are removed. The removal of the mucosa covering teeth allows, in several cases, second molars to erupt. The results of a previous study indicate that the retained permanent second molars still have the ability to erupt after surgical removal of the overlying mucosa and a delay could represent a temporary problem and not a failure of eruption [13]. 
In cases of anterior crowding or protrusion, incisors can be aligned and retracted to close the space due to missing posterior teeth. In contrast, in patients with no anterior crowding or protrusion, space can be closed through molar protraction, which can be challenging for clinicians [20].

Although prediction of third molar eruption is not an easy task [15], clinicians should consider that loss of lower first molars tends to improve third molar impaction. The changes that occur after the extraction may be associated with the age at extraction and the intercuspidation pattern [2]. However, because this study has a cross-sectional design, the timing of the first molar extraction could not be determined accurately and this hypothesis could not be tested.

A previous study showed a tendency for mandibular post-rotation in patients affected by infraocclusion of deciduous mandibular molars. Patients suffering from infraocclusion of the mandibular deciduous molars show mandibular post-rotation and an increased Total Gonial angle, compared to patients who do not suffer from infraocclusion. There is a hypothesis that mandibular post-rotation is promoted by infraocclusion and mesial inclination of deciduous lower molars [12].

For the eruption of mandibular third molars, the available space between the ascending ramus and the second molar is an important factor; therefore, securing space for third molars to erupt can reduce the incidence of impaction. If the first molar is hopeless and the third molar is impacted by mesialization of the second molar, the impacted third molar can be brought into occlusion without the need for dental implants $[21]$.

Regarding the impact of first molar loss and third molar development, the findings did not show any significant difference $(\mathrm{p}=0.07)$ when the third molar on the loss side was compared with that on the control side. The development of third molars was considered to be at the same stage in around $87 \%$ of the cases examined. Although the p-value is greater than 0.05, it is close to the statistically significant level, showing borderline non-significance. Therefore, missing first molar might be associated with the root development in the third molar with larger sample size. A previous investigation found no significant changes in the third molar vertical position after first molar loss. Thus, the present results do not support previous works in which the development of the third molars on the extraction side was reported to be significantly accelerated $[5,16]$.

This research used a more comprehensive and known radiographic view in the clinical area to perform the evaluation: panoramic radiographs. The advantage of these radiographs is that they provide a complete overview of dentition in relation to the dental development stage [15]. Their main disadvantage, however, is that they do not provide information on skeletal parameters; thus, it is difficult to evaluate dimensional changes accurately. Moreover, the two-dimensional feature of the images makes it impossible to read the changes occurring from an occlusal perspective. A thorough study of the influence of dental loss in the positioning and development of the lower third molars that includes long-term follow-up with the use of threedimensional images should be carried out. However, ethics issues could prevent patients who have undergone tooth extraction from receiving assistance, thus leaving them without treatment.

It seems reasonable to state that the loss of lower first permanent molars minimizes the occurrence of impaction of the third molars, increasing the space for eruption and allowing the mesial movement of the molars during the closing of space $[2,3,5,18,19]$. Thus, the extraction of lower first molars presenting extensive coronary destruction or the need for interventions in dismal prognosis can be considered when the patient presents a risk of impaction of the third molars. 


\section{Conclusion}

Loss of the lower first permanent molar can improve the eruption pattern of an impacted lower third molar adjacent to the loss but does not significantly affect the degree of root development of the adjacent lower third molar.

\section{Authors' Contributions}

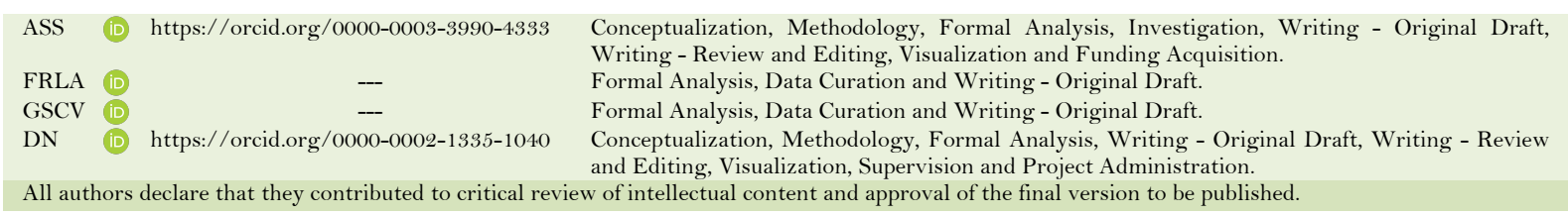

\section{Financial Support}

None.

\section{Conflict of Interest}

The authors declare no conflicts of interest.

\section{Data Availability}

The data used to support the findings of this study can be made available upon request to the corresponding author.

\section{References}

[1] Teo TK-Y, Ashley PF, Derrick D. Lower first permanent molars: developing better predictors of spontaneous space closure. Eur J Orthod 2016; 38(1):90-5. https://doi.org/10.1093/ejo/cjv029

[2] Normando ADC, Maia FA, Ursi WJ, Simone L. Dentoalveolar changes after unilateral loss of the lower first permanent molar and their influence on third molar development and position. World J Orthod 2010; 11(1):55-60.

[3] Normando ADC, Silva MC, Le Bihan R, Simone JL. Spontaneous occlusal changes after lower first permanent molar loss. Rev Dental Press Ortod Ortop Facial 2003; 8(3):15-23.

[4] Normando D, Cavacami C. The influence of bilateral lower first permanent molar loss on dentofacial morphology- a cephalometric study. Dental Press J Orthod 2010; 15(6):100-6.

[5] Halicioglu K, Toptas O, Akkas I, Celikoglu M. Permanent first molar extraction in adolescents and young adults and its effect on the development of third molar. Clin Oral Invest 2014; 18(5):1489-94.

https://doi.org/10.1007/s00784-013-1121-1

[6] Ghougassian SS, Ghafari JG. Association between mandibular third molar formation and retromolar space. Angle Orthod 2014; 84(6):946-50. https://doi.org/10.2319/120113-883.1

[7] Araújo RLA, Villela GSC. A influência da perda unilateral do primeiro molar permanente inferior no padrão eruptivo do terceiro molar inferior. [Monografia]. Belém (PA): Universidade Federal do Pará; 2002. 〔In Portuguese].

[8] Bishara SE. Third molars: a dilemma! Or is it? Am J Orthod Dentofacial Orthop 1999; 115(6):628-33. https://doi.org/10.1016/s0889-5406(99)70287-8

[9] Richardson ME. The lower third molar: an orthodontic perspective. Rev Dental Press Ortod Ortop Facial 1998; $3(3): 108-17$.

[10] Jälevik B, Möller M. Evaluation of spontaneous space closure and development of permanent dentition after extraction of hypomineralized permanent first molars. Int $J$ Paediatr Dent 2007; 17(5):328-35. https://doi.org/10.1111/j.1365-263X.2007.00849.x

[11] Abu Aihaija ES, McSheny PF, Richardson A. A cephalometric study of the effect of extraction of lower first permanent molars. J Clin Pediatr Dent 2000; 24(3):195-8.

[12] Lanteri V, Maspero C, Cavone P, Marchio V, Farronato M. Relationship between molar deciduous teeth infraocclusion and mandibular growth: a case-control study. Eur J Paediatr Dent 2020; 21(1):39-45. https://doi.org/10.23804/ejpd.2020.21.01.08.

[13] Farronato G, Giannini L, Galbiati G, Consonni D, Maspero C. Spontaneous eruption of impacted second molars. Prog Orthod 2011; 12(2):119-25. https://doi.org/10.1016/j.pio.2011.04.001

[14] Sisman Y, Uysal T, Yagmur F, Ramoglu SI. Third molar development in relation to chronologic age in Turkish children and young adults. Angle Orthod 2007; 77(6):1040-5. https://doi.org/10.2319/101906-430.1 
[15] Bastos AC, Oliveira JB, Mello KFR, Leão PB, Artese F, Normando D. The ability of orthodontists and oral/ maxillofacial surgeons to predict eruption of lower third molar. Prog Orthod 2016; 17(21):1-5. https://doi.org/10.1186/s405 10-016-0134-0

[16] Yavuz I, Baydas B, Ikbal A, Dagsuyu IM, Ceylan I. Effects of early loss of permanent first molars on the development of third molars. Am J Orthod Dentofacial Orthop 2006; 130(5):634-8. https://doi.org/10.1016/j.ajodo.2005.02.026

[17] Nolla CM. The development of permanent teeth. J Dent Child 1960; 4:254-66.

[18] Bayram M, Özer M, Selim A. Effects of first molar extraction on third molar angulation and eruption space. Oral Surg Oral Med Oral Pathol Oral Radiol Endod 2009; 107(2):e14-20. https://doi.org/10.1016/j.tripleo.2008.10.011

[19] Ay S, Agar U, Biçakçi AA, Köşger HH. Changes in mandibular third molar angle and position after unilateral mandibular first molar extraction. Am J Orthod Dentofacial Orthop 2006; 129(1):36-41. https://doi.org/10.1016/j.ajodo.2004.10.010

[20] Baik UB, Kang JH, Lee UL, Vaid NR, Kim YJ, Lee DY. Factors associated with spontaneous mesialization of impacted mandibular third molars after second molar protraction. Angle Orthod 2020; 90(2):181-6. https://doi.org/10.2319/050919-322.1

[21] Baik UB, Kook YA, Bayome M, Park JU, Park JH. Vertical eruption patterns of impacted mandibular third molars after the mesialization of second molars using miniscrews. Angle Orthod 2016; 86(4):565-70. https://doi.org/10.2319/061415-399.1 